\title{
PERCEPÇÃO DAS PESSOAS COM LESÃO MEDULAR SOBRE A SUA CONDIÇÃO
}

\author{
Ana Maria Fernandes BORGES ${ }^{\mathrm{a}}$, Paula BRIGNOL \\ Soraia Dornelles SCHOELLER ${ }^{\mathrm{c}}$, Albertina BONETTI ${ }^{\mathrm{d}}$
}

\section{RESUMO}

Este estudo tem como objetivo conhecer a percepção das pessoas com lesão medular sobre sua condição e investigar algumas de suas características. Estudo descritivo, de natureza qualitativa do tipo exploratória, realizado com vinte e cinco pessoas com lesão medular, participantes de um centro de reabilitação. Os dados foram coletados por entrevistas semiestruturadas, com base em roteiro. A organização, categorização e análise dos mesmos ocorreram segundo análise temática. Emergiram dos dados quatro categorias, além das características dos participantes: diferentes formas de percepção da sua condição; diferentes formas de enfrentamento à sua condição; família, o apoio essencial; e todos têm problemas a ser superados. As pessoas com lesão medular enfrentam e percebem sua condição de diferentes maneiras, relacionadas ao apoio familiar, a capacidade de se autogovernar, a realização de atividades da vida diária e estabelecimento de novos objetivos de vida. O conhecimento dessas questões é importante para a realização do cuidado em saúde.

Descritores: Medula espinal. Reabilitação. Autonomia pessoal. Enfermagem.

\section{RESUMEN}

Este estudio tuvo como objetivo conocer la percepción de las personas con lesión en la médula espinal sobre su condición e investigar algunas de sus características. Estudio cualitativo, descriptivo, desarrollado con veinticinco personas con lesiones de la médula espinal, recogiéndose los datos con entrevistas semiestructuradas. El análisis de contenido encontró que las personas con lesión medular enfrentan y se notan de manera diferente. Este hecho está directamente relacionado con la autonomía que tiene en su estado. El sentirse impotente, hace con que la persona con lesión de la médula espinal se sienta incapaz de gobernarse a sí misma, lo que puede desencadenar un efecto negativo en el proceso de rehabilitación en el cual la búsqueda de la autonomía es objetivo clave. Los resultados de esta investigación indican la necesidad de estudios para investigar más a fondo las diferentes estrategias que las personas con lesión medular utilizan para enfrentar su nueva condición.

Descriptores: Médula espinal. Rehabilitación. Autonomía personal. Enfermería.

Título: Personas con lesión medular y diferentes percepciones sobre su condición.

ABSTRACT

This study is aimed at finding out people's perception about their spinal cord injury condition and investigating some of their characteristics. A qualitative, exploratory and descriptive research was performed, in which 25 people with spinal cord injury of a rehabilitation center were interviewed. The data was collected through semi-structured interviews based on an outline. The organization, categorization and analysis were carried out according to a thematic analysis. Four categories emerged from the data and characteristics of the participants: different perceptions of their condition, different ways of coping with their condition; family, the essential support, and everybody has problems which need to be overcome. People with spinal cord injury face and perceive their condition in different ways, related to family support, self-governing ability, performing activities of daily living and setting new life goals. Knowing about these issues is important for health care implementation.

Descriptors: Spinal cord. Rehabilitation. Personal autonomy. Nursing.

Title: People with spinal cord injury and the different perceptions about their condition.

a Enfermeira. Mestranda do Programa de Pós-Graduação em Enfermagem da Universidade Federal de Santa Catarina (UFSC), Bolsista CNPq. Membro do Grupo de Pesquisa Práxis - Grupo de Estudos sobre Trabalho, Cidadania, Saúde e Enfermagem. Membro do Projeto de Extensão da UFSC - Grupo (Re)Habilitar. Florianópolis, Santa Catarina, Brasil.

b Enfermeira. Residente Multidisciplinar em Alta Complexidade do Hospital Universitário da UFSC. Membro do Projeto de Extensão da UFSC - Grupo (Re)Habilitar. Florianópolis, Santa Catarina, Brasil

c Enfermeira. Doutora em Enfermagem, Docente da Universidade Federal de Santa Catarina. Membro do Grupo de Pesquisa Práxis - Grupo de Estudos sobre Trabalho, Cidadania, Saúde e Enfermagem. Coordenadora do Projeto de Extensão da UFSC - Grupo (Re)Habilitar. Florianópolis, Santa Catarina, Brasil.

d Educadora Física. Doutora em Enfermagem. Docente da Universidade Federal de Santa Catarina. Membro do Grupo de Pesquisa NUCRON - Núcleo de Pesquisa em Enfermagem e Saúde no Cuidado a Pessoas com Doenças Crônicas. Membro do Projeto de Extensão da UFSC Grupo (Re)Habilitar. Florianópolis, Santa Catarina, Brasil. 


\section{INTRODUÇÃO}

O número de pessoas com alguma deficiência física tem aumentado na sociedade contemporânea, devido o envelhecimento geral da população, o aumento da sobrevida dos pacientes em razão dos melhores cuidados na fase aguda e o crescimento da violência e das lesões traumáticas daí decorrentes ${ }^{(1)}$. No Brasil avalia-se que a prevalência de deficientes físicos por paralisação de ao menos um membro ${ }^{(2)}$ é de 9,4 a cada mil habitantes.

Estima-se que $88 \%$ dos 85 milhões de pessoas com deficiência da América Latina não tenha assistência de saúde adequada, e que $10 \%$ da população mundial viva com alguma deficiência e sem acesso a direitos de cidadania ${ }^{(3)}$. Pobreza e deficiência estão fortemente articuladas: a deficiência é agravada pela falta de acesso a educação, informação, atenção em saúde e bens de consumo necessários ao enfrentamento da própria condição. Em contrapartida, o acesso a tecnologias assistivas minimiza os problemas ocasionados pela deficiência. Assim o tema deficiência precisa ser abordado em diferentes níveis: clínico, de reabilitação, social e político ${ }^{(3)}$.

Apesar do grande número de pessoas com deficiência, no Brasil são escassos os estudos em saúde voltados a esta temática e os profissionais de saúde carecem de maiores informações sobre as especificidades no processo saúde doença destas pessoas e, consequemente, das necessidades de cuidado que elas apresentam. Este estudo transita nesta lacuna de conhecimento.

A lesão medular é parte importante das deficiências físicas. A coluna vertebral é composta por sete vértebras cervicais $(\mathrm{C} 1$ a $\mathrm{C} 7)$, doze vértebras torácicas (T1 a T12), cinco lombares (L1 a L5) e cinco sacrais (S1 a S5). Quanto mais alto o nível, maior é o acometimento neurológico motor e sensitivo do corpo: tetraplegia - acima de $\mathrm{C} 7$, atinge os quatro membros - superiores e inferiores, e paraplegia - abaixo de T1, acomete membros inferiores. Sua classificação é determinada pela tabela da American Spinal Injury Association (ASIA) ${ }^{(1)}$, e varia de (A) a (E), sendo (A) lesão motora e sensitiva completa, (B) completa motora e incompleta sensitiva; (C) incompleta motora funcional, (D) incompleta motora não funcional e (E) com funções sensitivas e motoras preservadas.

A lesão medular é caracterizada pela perda da integridade física e mudanças da imagem corporal, o que pode levar à desestruturação psíquica ${ }^{(4)}$. Após seu diagnóstico, a pessoa se depara com uma condição grave e incapacitante por um longo período de tempo, ou mesmo para o resto da vida; há alterações na sua imagem corporal e a busca do reconhecimento da nova condição física, o que pode afetar sua relação com o mundo que a cerca. As mudanças são expressas nas mais diversas reações, desde as mais exacerbadas até aquelas inexpressivas, que estão articuladas com as condições psicológicas, sociais e econômicas, além de outras intrínsecas à própria pessoa. As pessoas com lesão medular podem apresentar "[...] agressividade, insegurança, ansiedade, impulsividade, isolamento social, desespero, sentimento de inferioridade, ambivalência, raiva, medo e desesperança" ${ }^{\text {(4). }}$. Esta deficiência constitui na atualidade uma "epidemia global" e de custo social altíssimo ${ }^{(5)}$.

Este estudo objetivou conhecer a percepção da pessoa com lesão medular sobre a sua condição e investigar algumas de suas características: idade, sexo, tempo, causa e nível da lesão medular, numa tentativa de contribuir para o cuidado em saúde.

A definição de percepção distingue-a em três eixos: um significado geral, referente à atividade cognitiva geral; o ato ou função cognitiva pela qual se apresenta um objeto real; e a ação do homem em suas relações com o ambiente. No primeiro ela não se separa do pensamento; o segundo envolve o conhecimento empírico; e, o terceiro parte da interpretação dos estímulos ${ }^{(6)}$. Nesta ótica a percepção está relacionada à condição de cada pessoa no mundo, envolvendo sua exterioridade e interioridade. A percepção é algo dual relacionada à imagem que nos é apresentada. Nossa percepção delineia, no conjunto das imagens, as ações virtuais ou possíveis do nosso corpo, o que resulta nas possibilidades de ação, sendo um processo - percepção, reflexão, ação ${ }^{(7)}$.

\section{METODOLOGIA}

Foi uma pesquisa qualitativa descritiva, do tipo exploratória. O local de realização foi um centro de referência em reabilitação no Estado de Santa Catarina. Os sujeitos do estudo foram pessoas com lesão medular participantes do programa de reabilitação deste centro, que procuraram o serviço de enfermagem nos meses de agosto a outubro de 2010. Foram critérios de inclusão: possuir lesão medular independente do tempo, nível ou classificação da lesão; ter capacidade de comunicação; não ter tido lesão cerebral. Os critérios de exclusão foram: não aceitar participar da pesquisa, ter tido lesão cerebral além da medular. Desses critérios resultaram vinte 
e cinco pessoas entrevistadas, identificadas com a letra $\mathrm{P}$ (participante) e o número correspondente à entrevista, para garantir o anonimato. Foi respeitada a Resolução 196/96, sendo esta enviada ao Comitê de Ética e Pesquisa em Seres Humanos da Universidade Federal de Santa Catarina e aprovada pelo parecer número 884 em 26/07/10.

$\mathrm{Na}$ coleta dos dados foram utilizadas a entrevista semi-estruturada e a análise documental. Para a realização da entrevista houve a abordagem das pesquisadoras aos participantes do estudo, que foram esclarecidos quanto aos objetivos, método e análise dos dados da pesquisa, e esta foi por eles autorizada através da assinatura ou autorização gravada do Termo de Consentimento Livre e Esclarecido. No caso do participante ter 16 anos ou menos, foi solicitada a aprovação dos pais, e estes acompanharam a entrevista. Foram coletadas informações referentes à lesão, escolaridade, condições sócio-econômicas, família, atividades da vida diária realizadas e percepção sobre a sua condição de pessoa com lesão medular. A análise documental foi realizada nos prontuários destes participantes para complementar dados relacionados ao nível da lesão e atividades da vida diária.

O registro dos dados foi feito por gravação e posterior transcrição, e para análise dos dados utilizou-se de análise temática, que tem como perspectiva a compreensão dos significados no contexto da fala ${ }^{(8)}$. Os dados foram organizados utilizando-se o software ATLAS-ti, com os seguintes passos: apreensão, síntese e teorização. A apreensão envolveu a imersão nos dados com leituras sucessivas das entrevistas, seguida da codificação a partir da segmentação e identificação das unidades de significado. Esses códigos foram agrupados por semelhança, selecionados os mais relevantes ao estudo, formando a categoria. Durante este processo, a revisão bibliográfica foi utilizada como referência e base para a organização, análises e interpretações. O presente estudo é resultado do trabalho de conclusão de curso do curso de graduação em Enfermagem da Universidade Federal de Santa Catarina ${ }^{(9)}$.

\section{RESULTADOS E DISCUSSÃO}

\section{Caracterização dos sujeitos da pesquisa}

A idade dos participantes variou de 14 a 77 anos, sendo dos 14 a $21 \operatorname{anos}(32 \%), \operatorname{dos} 22$ a 30 anos (12\%), dos 31 a $50 \operatorname{anos}(52 \%)$, dos 51 a 77 anos (4\%). São representados pelo sexo masculino neste estudo $88 \%$ dos participantes, com lesão adquirida pela violência (ferimento por arma de fogo $-40 \%$, acidente de trânsito $-28 \%$, quedas e acidente de trabalho-20\%). O tempo da lesão foi de 4 meses a 14 anos, muitos dos quais com menos de quatro anos de lesão $(72 \%)$. A idade na ocorrência do trauma oscilou entre 3 a 63 anos, onde dos 3 a $15 \operatorname{anos}(14 \%), \operatorname{dos} 16$ a 25 anos (36\%), dos 26 a 35 $(28 \%), \operatorname{dos} 36$ a $50(28 \%), \operatorname{dos} 51$ a 60 anos (4\%). A escolaridade variou entre ensino fundamental e superior completo, este último somente com uma pessoa (4\%). Quanto ao estado civil, há um equilíbrio entre solteiros e casados e, excetuando duas pessoas, todas moram com suas famílias. Sobre o nível e classificação da lesão dos participantes estes variaram da segunda vértebra lombar (L2) a quarta vértebra cervical (C4), e classificação da American Spinal Injury Association (ASIA) (A) a ASIA (D), predominando as paraplegias completas, ASIA (A).

Em relação ao grau de independência das pessoas, dado pela realização das atividades da vida diária (AVD), tornou-se evidente alguma dependência, especialmente no cateterismo vesical e transferências. Vários métodos avaliam a independência funcional ${ }^{(10)}$. No Brasil ${ }^{(11)}$ são utilizados a Classificação de Independência Funcional (CIF) e a Medida de Independência Funcional (MIF). Ambas são adotadas pelos serviços de reabilitação para que a pessoa com deficiência física possa conhecer suas limitações e potencialidades. Elas classificam a independência funcional através da capacidade de realizar individualmente algumas tarefas como vestuário, higiene, alimentação, auto cateterismo, esvaziamento intestinal e transferências.

Os participantes da pesquisa independentes para as AVD possuem o nível da lesão entre L1 (paraplegia) a C8 (tetraplegia) e a classificação ASIA entre (A) a (D) com tempo de lesão entre 10 meses a 14 anos. Já, os dependentes para as AVD possuem o nível da lesão entre L2 (paraplegia) a C4 (tetraplegia), também variando de ASIA (A) a (C), sendo o tempo da lesão de 4 meses a 4 anos e 6 meses $(80 \%)$.

\section{Lesão medular: diferentes percepções}

Os participantes da pesquisa expressaram-se de diferentes formas e com diferentes percepções sobre sua condição. As respostas abrangeram um largo espectro de possibilidades, desde a sensação de 
total impotência para o vivenciar da nova condição, até o estabelecimento concreto de metas a serem perseguidas gradativamente, que resultassem na autonomia do sujeito, enquanto pessoa com capacidade de se autogovernar.

Neste intervalo, houve pessoas que avaliaram que a lesão medular não constituía questão a ser considerada:

Mas eu não me acho diferente, não me considero diferente, vou aonde eu quero, apesar de não ser independente, mas aonde eu quero ir tem quem me leve [...] participo das coisas que quero participar, então eu não me acho diferente, por estar sentado numa cadeira de rodas (P9).

As diferentes percepções da pessoa com lesão medular estão relacionadas à autonomia que esta possui ou quer construir:

Sou uma pessoa que por ter ficado deficiente das minhas pernas, eu não deixo de ser uma pessoa igual às outras, só porque dependo da cadeira de rodas, porque elas são as minhas pernas (P12)

Esta autonomia inclui a liberdade de escolha e de ação e controle sobre a vida, representando a possibilidade de se autogovernar, e não somente de ser independente para as AVD.

O sentir-se impotente diante de uma situação, faz com que a pessoa com lesão medular sinta-se incapaz de se autogovernar, o que pode desencadear um efeito negativo no processo de reabilitação no qual a busca da autonomia é um dos principais objetivos.

Todos os participantes mencionaram o aumento de dificuldades e limitações com a lesão. Porém, foram construídas diferentes estratégias para seu enfrentamento, gerando percepções diferentes sobre sua condição, numa relação dialética entre autonomia x capacidade de se autogovernar e percepção sobre sua condição.

Cabe à sociedade possibilitar o enfrentamento da nova situação de deficiência na construção da autonomia. Isto vai ao encontro da Legislação - Lei $n^{\circ} 10.098$ sancionada em 2000 que estabelece normas gerais e critérios básicos para a promoção da acessibilidade das pessoas portadoras de deficiência ou com mobilidade reduzida ${ }^{(12)}$. Mesmo assim, são encontradas várias dificuldades que fazem com que a pessoa perceba-se diferente dos demais e tente estabelecer estratégias para enfrentar, além de sua condição, os desafios impostos pela própria sociedade.
O enfrentamento a "[...] uma adaptação bem sucedida está positivamente associado à adoção de estratégias focadas no problema, como busca do suporte social e percepção de controle sobre a própria saúde" ${ }^{\prime 13)}$.

Diversas estratégias são construídas para o enfrentamento da condição de lesão medular e uma pessoa pode utilizar uma ou mais delas ${ }^{(13)}$, que geram diferentes percepções sobre sua condição enquanto pessoa com lesão medular. A seguir, apresentamos as subcategorias relacionadas a estas estratégias, evidenciadas neste estudo: Lesão medular: diferentes enfrentamentos; A família e entorno: apoio essencial; Todos têm problemas a serem superados.

\section{Lesão medular: diferentes enfrentamentos}

Foram agrupadas nesta categoria a impossibilidade de superar a nova condição e a possibilidade de enfrentar, ambas relatadas nas falas dos participantes.

A sensação de impossibilidade está relacionada ao sentimento de perda. A pessoa sente-se incapaz de se autogovernar, devido a sua dependência e à falta de controle sobre si mesma. Ela não se sente capaz de escolher quaisquer caminhos ou de agir sobre sua vida, ficando completamente à mercê de outrem.

Há, assim, a perda de si mesmo e o sujeito ideal é aquele anterior à nova condição, havendo a valorização da perda e do passado, em detrimento das capacidades restantes, pois parecem sem utilidade e sem perspectivas de mudança ou melhora.

[...] antes eu podia cuidar de mim mesmo, podia me virar [...] podia pedir ajuda de alguém, mas eu era o principal que podia me ajudar. [...] agora não, agora eu estou totalmente vulnerável a tudo, se não tiver alguém ali do meu lado, pra me dar água, eu posso morrer de sede, fome, de vez em quando eu fico tonto, passo mal, desmaio, ai se não tiver alguém do lado [...] eu sozinho, estou totalmente vulnerável, desprotegido [...] (P15).

Os sentimentos se confundem, afetando o processo de reabilitação. No entanto, é comum e esperado que isto ocorra nas várias fases da reabilitação. Desamparo, fraqueza, depressão, rejeição do novo modo de vida, auto-imagem distorcida e insegurança, fazem parte do cotidiano das pessoas que convivem com mudanças bruscas em suas vidas ${ }^{(14)}$. 
Nas falas que evidenciaram a possibilidade de superar sua nova condição de vida, as limitações impostas pela lesão medular levam a pessoa a reconhecer sua condição e construir metas pequenas e constantes:

[...] eu estou lutando para minha escara sarar, não é? [...] Eu sei que ela já está bem menor, então já é uma luta que eu estou vencendo. Têm outras lutas para eu vencer, para eu tomar banho, trocar a minha roupa. São outras lutas que eu ainda vou começar, mas é uma coisa de cada vez. Enquanto eu não conseguir, eu não paro e vou lutando para aquilo até conseguir. Então por isso, eu me acho um lutador [...] (P10).

É um processo complexo que exige mudanças constantes nos hábitos e costumes no qual a questão central é o reconhecimento de que, apesar das grandes mudanças é possível tocar a vida com qualidade e ter planos, como podemos evidenciar nos depoimentos:

[...] a vida não é fácil, a gente vai aprendendo tudo de novo, não é? Quando nasce a gente tem que aprender a engatinhar, não é? E a gente vai aprender tudo diferente de novo, só não vamos andar mais, muda tudo $\operatorname{assim}\left(P_{17}\right)$.

[...] tudo parte do princípio de a gente estimular, não vou desanimar [...] tenho muito tempo ainda para tentar, muito tempo, não sei quando eu vou morrer ninguém sabe. Mas eu tenho muito tempo para tentar e para não desistir, nem que eu leve uns 30 anos [...] (P19).

O sucesso está positivamente associado à adoção de estratégias focadas no problema, como busca de suporte social e percepção de controle sobre a própria saúde ${ }^{(13,15)}$

Todo dia eu tenho uma meta, eu tava na cama, não conseguia fazer nada, e todo dia eu tinha uma meta, a primeira meta foi comer sozinho, depois respirar, porque eu tava respirando mal, e depois foi mudar para cadeira, tirar as feridas que eu tinha, que é a pior coisa que existe e que hoje eu não tenho mais, várias coisas, mas todo dia tu tens uma meta (P24).

A pessoa com lesão medular, ao estabelecer estratégias concretas para o enfrentamento de suas limitações torna-se capaz de superar seus limites, com alta governabilidade sobre si, autônoma, confiante em si e dependendo cada vez menos dos seus potenciais cuidadores.

\section{A família e o entorno: apoio essencial}

A busca de redes de apoio para suporte é uma das estratégias de enfrentamento adotadas pelas pessoas com lesão medular, especialmente o apoio familiar e o companheirismo das amizades:

A minha força de vontade surge em vários sentidos, pela minha mãe, pela minha esposa, pelo meu fisioterapeuta e vem de Deus também,eu agradeço rezando. Porque eu fiquei 47 dias no internado e o médico disse pra minha esposa que eu nunca mais voltaria a andar. Eu sei que $100 \%$ eu não voltarei a ser, mas eu posso me superar o máximo possível, porque eu tenho que aprender a me adaptar a minha casa (P1).

O suporte social é relevante no processo de reabilitação, proporcionando melhor adaptação às limitações ocasionadas pela lesão medular. A família é o alicerce que influencia na percepção da pessoa sobre si mesma.

A rede social pode ser formada pela família, por grupos de amigos, pelas igrejas, pelas associações de bairro ou pelas associações de pessoas que convivem com uma mesma doença, pelos vizinhos, instituições de saúde, pelos centros de cura não formais, sendo considerada essencial na promoção, prevenção da saúde e reabilitação das pessoas. Por meio destas, "podem ser trabalhadas condições que influenciam o comportamento, oportunizando várias estratégias de intervenção, através de um tecido de relações e interações"(16).

Nos depoimentos, constatamos a importância e a necessidade destas interações e do compartilhar, saberes, valores, crenças, apoio e ajudas mútuas, que repercutem no processo de viver.

A qualidade de vida das pessoas com lesão medular está relacionada à reabilitação, processo que facilita a adaptação à nova condição pela construção de alternativas para a independência funcional, melhora da auto-estima e inclusão social ${ }^{(17,18)}$. A sua percepção positiva diante da sua condição interfere na qualidade de vida, e, para que isso é necessária a presença da família. É o entorno familiar quem tem a responsabilidade direta sobre o cuidado à pessoa, estimulando-a a assumir estratégias de enfrentamento às limitações, na busca da autonomia e autogoverno.

No entanto, a família também necessita de apoio, pois ela também está inserida no processo de reabilitação, apesar de somente um membro possuir 
deficiência. Assim todos se consideram afetados pela nova condição de vida do familiar ${ }^{(13)}$.

A adaptação é ocorre quando a pessoa interage com o ambiente. Ela pode adotar diferentes maneiras para enfrentar as diversas situações, agindo de diferentes maneiras às mesmas situações, dependendo dos recursos pessoais, ambientais e familiares disponíveis.

\section{Todos têm problemas a serem superados}

Uma categoria encontrada nas falas dos participantes refere ao entendimento de que todas as pessoas possuem problemas a serem superados, e que a lesão medular é um problema a mais, e não o determinante dos demais problemas. Tal postura foi associada a idade em que ocorre o trauma.

A idade em que ocorre a lesão é um ponto importante no processo de enfrentamento, mostrando que, adultos que sofreram lesão medular na infância apresentam menos problemas de adaptação do que pessoas que adquiriram a lesão durante a fase $\operatorname{adulta}^{(14)}$ : a percepção da pessoa com lesão medular também difere de acordo com o momento em que ocorreu a lesão.

É possível que seja mais fácil para a pessoa que sofreu lesão na infância adaptar-se melhor do que o adulto. Este deve substituir uma rotina já existente e construída por longo tempo, por outra completamente diferente. Enquanto a criança adapta-se ao seu corpo e ao meio externo já com as limitações físicas presentes, o adulto, precisa desenvolver novos mecanismos para realizar atividades antes feitas sem dificuldades ${ }^{(14)}$.

As limitações acontecem independentemente da idade da lesão, ou até da idade da pessoa. O que muda é a percepção da pessoa, pois quando adulto a imagem de sua condição anterior de não deficiente é muito presente enquanto que, quando a lesão ocorre na infância, a imagem predominante é a da atual condição física, conforme a fala de uma pessoa que adquiriu lesão medular aos três anos de idade:

Sinto-me feliz, adaptado, tranquilo com a vida que levo. […] afinal são 11 anos (P18).

Há, ainda, casos em que sua percepção está intrínseca ao processo de viver, pois há um sentimento de normalidade perante a sua condição. Seja por não ter vivenciado outra situação em sua vida ou por estar completamente adaptado.
Estou continuando com a minha vida, após a lesão, fazendo faculdade. Eu não trabalho ativamente, mas a minha família tem uma empresa, então eu acabo ajudando. É, eu vou seguindo (P21).

É evidente que a percepção varia de acordo com a forma que ela encara a sua nova condição de vida. Esta nova condição possibilita a ressignificação de sua existência, percebendo novas possibilidades de participar ativamente na sociedade, resgatando a auto-estima, o gosto pela vida, na busca constante por superação das dificuldades, tendo, como conseqüência, a melhora da sua condição de vida ${ }^{(19)}$.

\section{CONSIDERAÇÕES FINAIS}

Das pessoas com lesão medular deste estudo $52 \%$ possuem entre 31 a 50 anos e $88 \%$ são do sexo masculino e adquiriram a lesão por violência. Sua percepção sobre a condição de pessoa com lesão medular é diversificada, e está intimamente relacionada às estratégias encontradas individualmente $\mathrm{e}$ ao entorno familiar.

A adaptação à nova condição passa por diversas fases, não a impedindo de continuar a desenvolver suas metas, seus planos e trabalhar para melhorar sua qualidade de vida, continuar a estabelecer perspectivas e manter suas expectativas de vida, inclusive ampliando as possibilidades de superação. O enfrentamento da nova condição da pessoa com lesão medular dado pelo estabelecimento de metas concretas e passíveis de serem atingidas faz com que esta se torne autônoma e com capacidade de se autogovernar, visto que a autonomia da pessoa com lesão medular não está relacionada, exclusivamente, ao seu nível de lesão, ou à sua classificação de independência funcional.

Os achados desta pesquisa apontam para a necessidade de estudos que aprofundem as diversas estratégias que as pessoas com lesão medular utilizam para enfrentar sua nova condição, assim como quais as percepções que elas possuem diante da condição física, uma vez que a percepção não está diretamente relacionada ao nível ou gravidade da lesão.

\section{REFERÊNCIAS}

1 American Spinal Injury Association [Internet $]$. [Homepage] [2010] [citado 2010 jul 05]. Disponível em: http://www.asia-spinalinjury.org/. 
2 Castro SS, Cesar CLG, Carandina L, Barros MBA, Alves MCGP, Goldbaum M. Deficiência visual, auditiva e física: prevalência e fatores associados em estudo de base populacional. Cad Saúde Pública. 2008; 24 (8): 1773-1782.

3 Elias MP, Monteiro LMC, Chaves, CR. Acessibilidade a benefícios legais disponíveis no Rio de Janeiro para portadores de deficiência física. Cienc Saude Colet. 2008; 13 (3):1041-1050.

4 Fechio MB, Pacheco KMB, Kaihami HN, Alves VLR. A repercussão da lesão medular na identidade do sujeito. Acta Fisiátrica. 2009; 16 (1): 38-42.

5 Internacional Compaign for cures of spinal injury Paralysis. General Information [Internet] 2011 [citado 2012 jan 23] Disponível em: http://www.campaignforcure.org/iccp/index. php?option $=$ com_content $\&$ task $=$ view $\&$ id $=13 \&$ It emid $=28$

6 Worms F. Le Vocabulaire de Bergson. Paris: Ellipses; 2000

7 Ferraz MCF. Percepção, imagem e memória na modernidade: uma perspectiva filosófica. Intercom. 2004; 17 (1): 59-78.

8 Minayo MCS. O desafio da pesquisa social. In: Minayo MCS, Delandes SF, Gomes R. Pesquisa social: teoria, método e criatividade. $28^{\text {a }}$ ed. Rio de Janeiro: Vozes; 2010. p. 9-79

9 Borges AMF, Brignol P. Percepção da pessoa com lesão medular sobre a sua condição [Trabalho de Conclusão de Curso]. Florianópolis: Curso de Graduação em Enfermagem, Universidade Federal de Santa Catarina; 2010.

10 Cacho E, Melo FRLV, Oliveira R. Avaliação da recuperação motora de pacientes hemiplégicos através do protocolo de desempenho físico Fugl-Meyer. Rev Neur. 2004; 12 (2): 94-102.

\section{Endereço da autora / Dirección del autor / Author's address}

Ana Maria Fernandes Borges

Rua João Meirelles, 884, Bloco C, ap. 206, Abraão

88085-201, Florianópolis, SC

E-mail: a.fborges@yahoo.com.br
11 Farias N, Buchalla CM. A Classificação Internacional de Funcionalidade, Incapacidade e Saúde da Organização Mundial da Saúde: conceitos, usos e perspectivas. Rev Bras Epidemiol. 2005; 8(2): 187-193.

12 Brasil. Lei n. 10098, de 19 de dezembro de 2000: estabelece normas gerais e critérios básicos para a promoção da acessibilidade das pessoas portadoras de deficiência ou com mobilidade reduzida, e dá outras providências. Brasília (DF); 2000.

13 Murta S, Guimarães SS. Enfrentamento à lesão medular traumática. Estud Psicol. 2007; 12 (1): 57-63.

14 Pereira MESM, Araújo TCCF. Enfrentamento e reabilitação de portadores de lesão medular e seus cuidadores. Psico. 2006; 37 (1): 37-45.

15 Livneh H. Psychosocial adaption to spinal cord injury: the role of coping strategies. JARC. 2000; 31: 3-10.

16 Meirelles BHS. Viver saudável em tempos de Aids: a complexidade e a interdisciplinaridade no contexto da prevenção da infecção pelo HIV [tese]. Florianópolis: Programa de Pós Graduação em Enfermagem, Universidade Federal Santa Cantarina; 2003.

17 Vall J, Braga BAV, Almeida PC. Estudo da qualidade de vida em pessoas com lesão medular traumática. Arq Neuropsiquiatr. 2006; 64(2B):451-455.

18 Venturini DA, Decesaro MN, Marcon SS. Conhecendo a história e as condições de vida de indivíduos com lesão medular. Rev Gaúcha Enferm. 2006 jun;27(2):2 19-29.

19 Costa VSP, Melo MRAC, Garanhani ML, Fujisawa DS. Representações sociais da cadeira de rodas para a pessoa com lesão da medula espinhal. Rev Latino-Am Enferm. [Internet]. 2010 [citado $2011 \mathrm{mar}$ 12]; 18(4): 755-762. Disponível em: http://www. scielo.br/scielo.php? script $=$ sci_arttext\&pid=S0104$11692010000400014 \& \operatorname{lng}=$ pt. doi: 10.1590/So 10411692010000400014 .

Recebido em: 18.05.2011

Aprovado em: 22.03.2012 